\title{
Redução de Custos Operacionais em Indústrias de Manufatura de MDF
}

\section{Operating Costs Reducing in MDF Manufacturing Industries}

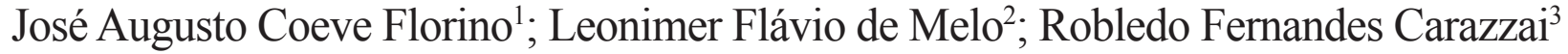

\section{Resumo}

Os esforços sofridos pelos motores elétricos quando submetidos a operações de corte, desbaste ou acabamento estão relacionados diretamente com o material que está sendo usinado e o ângulo de ataque da ferramenta. A escolha da ferramenta correta para tal operação depende de um resultado esperado. Assim os motores comportam-se de forma diferente a cada operação. A otimização entre força, velocidade, potência, material e tipo de operação, podem ser encontrados para a redução de custos operacionais de produção, além da determinação do exato momento para efetuar o set-up da ferramenta desgastada. A redução dos custos operacionais é um dos itens de sustentabilidade que traça o posicionamento estratégico nas empresas para as tornarem competitivas no mercado globalizado. Com o grande desenvolvimento tecnológico presente hoje em dia, este assunto volta a ser apresentado com o que há de mais moderno no mercado de produtos para profissionais que desenvolvem atividades de manutenção. De maneira prática os problemas de custo operacional mínimo e maior produtividade serão abordados com equipamentos presentes na manutenção moderna como analisador de qualidade de energia, termovisor, projetor de perfil e microscópio para as pesquisas. O resultado do trabalho é a otimização entre a operação de corte e o consumo de energia elétrica mostrando assim um ponto ótimo de operação em um estudo de caso apresentado no decorrer do trabalho.

Palavras-chave:Técnicas de manutenção preditiva. Redução de custos operacionais. Gestão de produção. Análise e tomada de decisão. Operação de usinagem.

\begin{abstract}
The sustained efforts by electric motors when subjected to cutting, trimming or finishing are directly related to the material being machined and the angle of attack of the tool. Choosing the right tool for this operation depends on an expected result. So the engines behave differently to each operation. The optimization between strength, speed, power, material and type of operation, can be found to reduce operational costs of production, besides determining the exact time to make the set-up of worn tool. The reduction in operating costs is an item of sustainability that outlines the strategic positioning on companies to become competitive in the global marketplace. With the great technological development present today, this issue goes away with the very latest products on the market for professionals who
\end{abstract}

1 Mestre formado noDepartamento de Engenharia Elétrica da Universidade Estadual de Londrina - DEEL-UEL,Engenheiro Eletricista, Engenheiro de Produção Mecânica e Coordenador do Curso de Engenharia de Produção da Universidade Sagrado Coração em Bauru/SP - CCESA- USC; jose.florino@usc.br;

2 Prof. Dr. do Departamento de Engenharia Elétrica da Universidade Estadual de Londrina - DEEL-UEL; leonimer@uel.br;

3 Aluno de mestrado do Departamento de Engenharia Elétrica da Universidade Estadual de Londrina - DEEL-UEL; rcarazzai@, gmail.com; 
carry out maintenance activities. As a practical problem of the minimal operating cost and higher productivity will be dealt with in these modern maintenance equipment such as power quality analyzer, Imager, profile projector and microscope for research. The result of this work is the optimization of the cutting operation and energy consumption thereby demonstrating an optimum point of operation in a case study presented in this work.

Key words: Predictive maintenance techniques. Reduced operating costs. Production management. Analysisand decision making. Machining operation.

\section{Introdução}

Com o crescente aumento da demanda de produção as indústrias tendem a adotar estratégias competitivas e a sustentabilidade torna-se um fator determinante para a continuidade da atuação no mercado cada vez mais estratégico.

Controlar custos de produção, que são os fatores que contribuem significantemente para o crescimento do preço de venda do produto. Uma estratégia determinante para uma empresa continuar no mercado, uma vez que o consumidor busca baixo custo com alta qualidade.

O preço de venda dos produtos industrializados apresentam aspectos onde o mercado consumidor é quem determina o preço final de venda. Admitindo dentro dos custos operacionais os custos de implantação de um sistema automatizado, o tempo de retorno dos investimentos, comumente chamado de payback, será em um menor tempo. Possibilitando assim o empresário focar novos investimentos com um curto espaço de tempo.

Uma teoria do preço de venda do produto, que pode ser observada na Figura 1, o que exige das indústrias de transformação uma redução seus custos fixos e de produção para manter uma margem de lucro aceitável (SLACK; CHAMBERS; JOHNSTON, 2008).

Figura 1 - Teorema das equações do preço de venda do produto.

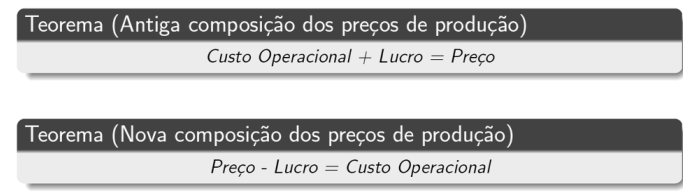

Fonte: Slack, Cham-Bers e Johnston (2008).
Admitindo dentro dos custos operacionais os custos de implantação de um sistema automatizado, o tempo de retorno dos investimentos, comumente chamado de payback, será em um menor tempo. Possibilitando assim o empresário focar novos investimentos com um curto espaço de tempo.

O papel do valor em dinheiro em uma operação no tempo que envolve gastos, as decisões financeiras podem ser aferidas por meio de técnicas (GITMAN; JUCHAU; FLANAGAN, 2000).

As ferramentas de corte utilizadas nas indústrias são partes de um processo de manufatura onde se agrega valor a uma determinada matéria prima, tornando um simples pedaço de madeira em um objeto de utilização pelo mercado consumidor.

A Troca Rápida de Ferramentas (TRF) pode ser um diferencial para aumento da disponibilidade dos equipamentos (LEÃO; SANTOS, 2009).

Para garantir a estabilidade do processo deve-se evitar que as máquinas quebrem ou gerem variações na produção (ISHIKAWA, 1993).

As empresas de classes mundiais estão inseridas em um contexto global e tornando-se cada vez mais visível a necessidade de se ter um produto competitivo que possa agregar valor ao negócio com uma eficiência operacional cada vez maior.

Um dos fatores que ocasionam paradas do processo produtivo é o desgaste de ferramentas, devem-se aliar as paradas para TRF com pequenas intervenções das diferentes técnicas de manutenção (ISHIKAWA, 1993).

As ferramentas de corte das máquinas são impulsionadas por motores, geralmente elétricos (FERRARESI, 1977). 
Os motores elétricos são peças importantes dentro do contexto industrial, sendo um consumidor de energia elétrica em potencial (MAMEDE FILHO, 2007).

A energia elétrica tem participação preponderante na vida do ser humano, sendo uma das bases de sustentabilidade e desenvolvimento das grandes empresas preocupadas com o meio ambiente (REIS; CUNHA, 2006).

A gestão e o planejamento de um sistema integrado de energia elétrica sãoum desenvolvimento sustentável no qual se se baseiam em métodos e procedimentos (REIS; CUNHA, 2006).

Uma estratégia a ser desenvolvida é o monitoramento de motores elétricos para as operações mecânicas de usinagem,pois os motores elétricos apresentam características diferentes quando submetidos a essas operações mecânicas como corte, desbaste ou acabamento. Um método para o monitoramento de suas variáveis irá refletir diretamente no rendimento da operação e em custos operacionais de produção (YIN; GRASSI, 2001).

Atualmente, a importância da qualidade padronizada em produtos torna-se algo de extrema relevância, tendo em vista o papel decisivo por ela assumido em face do processo de globalização, da abertura dos mercados e da consequente competitividade entre organizações.

Os processos e modelos que fazem parte do universo da gestão estratégica possibilitam o incessante aprimoramento das empresas, que a todo instante são estimuladas a alterar suas sistemáticas e procedimentos na tentativa de obter maiores níveis de competitividade.

A tomada da decisão baseada em fatos é muito importante para a obtenção dos objetivos propostos pelas organizações e a compatibilização de várias áreas de conhecimento acrescenta uma maior credibilidade para garantir os melhores resultados.

O objetivo do trabalho é de traçar melhor dimensionamento entre máquina e ferramentas para garantir a qualidade dos produtos e a sustentabilidade da empresa até mesmo o desenvolvimento e aperfeiçoamento de variáveis que influenciaram nos resultados.

Buscar o fator determinante do excessivo gasto de energia elétrica, advindo do uso de maquinas, equipamentos e ferramentas. Identificar métodos e maneiras para minimizar esses gastos, objetivando um menor consumo de energia, e ferramentas com qualidade e tempo de vida útil correto para utilização com economia, visando uma produção mais enxuta e rentável.

Os valores para a afiação e aquisição de ferramentas de corte da máquina em estudo foram levantados e analisados.

O consumo de energia elétrica nominal do motor, nominal durante o corte com a ferramenta em perfeita condições de corte e o nominal durante o corte com a ferramenta já em condições de uso intenso estão sendo abordados.

Com a redução dos custos de produção o lucro será maior e consequentemente a empresa conseguirá obter maior rentabilidade de sua atividade de produção e assim permanecer competitiva no mercado.

Os impactos ambientais reduzidos de forma sistêmica devido consumo excessivo de energia elétrica nas operações mecânicas de corte em painéis de madeira reconstituída serão uma consequência dos vetores influentes na questão ambiental.

\section{Metodologia}

O trabalho em questão auxiliará na determinação da necessidade de parada para set-up, a parada está sendo baseada na analise de comportamento do motor. A pesquisa foi realizada numa empresa de produção de móveis tendo como matéria prima chapas de MDF.

A operação de usinagem de materiais é realizada por quase todas as indústrias de manufatura, pois se trata de operações de grande importância e 
significância dentro do processo de manufatura de peças e ou produtos.

O inicio dos estudos foi com a monitoração do motor responsável por impulsionar a serra, ferramenta esta em perfeito estado de afiação para posterior verificação da melhor condição de trabalho.

Foram levantados os custos do motor operando em várias condições onde pode observar que em um determinado ponto o consumo de energia elétrica foi maior do que os custos para a substituição da ferramenta já desgastada.

A ajuda de softwares e equipamentos para profissionais envolvidos com a manutenção de máquinas e equipamentos estão sendo utilizados para a base do banco de dados e monitoramento.

Foram necessários os equipamentos como, amperímetro, multímetro, planilhas, o Analisador de Qualidade de Energia Trifásico Fluke Série 435, câmera de termovisão da Fluke Ti25, Projetor de Perfil e Microscópio.

$\mathrm{O}$ analisador de qualidade na energia utilizado no trabalho foi escolhido devido a grande possibilidade de obtenção de parâmetros elétricos simultaneamente um único equipamento como: corrente, tensão e frequências. Tal equipamento dispõe e pontas de provas que são ligadas a maquina ou ao equipamento específico, para seu estudo e posterior obtenção dos dados.

Com a câmera de termovisão FLUKE Ti25, foi possível a obtenção de dados dos pontos de aquecimentos decorrentes do processo de seccionamento de placas de madeira reconstituída do tipo MDF.

O projetor de perfil foi utilizado para a comparação dos estados da ferramenta antes e depois de serem submetidas à operação mecânica de corte.

Já para a obtenção das imagens reais da ferramenta foi utilizado um microscópio onde pode ser observado e comparado o desgaste da ferramenta de forma visual.

\section{Aplicações Tecnológicas}

Em uma determinada parte do processo de manufatura de uma empresa do ramo de móveis, especificamente na operação de corte de chapas de MDF com espessura de $15 \mathrm{~mm}$ de eucalipto, para que sejam produzidas pedaços das placas de madeira reconstituída nos tamanhos desejados.

O motor responsável pelo movimento da serra é do tipo indução trifásico, com $7,5 \mathrm{cv}$ de potencia, tensão de trabalho 220vac e rotação de $3600 \mathrm{rpm}$.

A serra que está sendo utilizada neste processo possui 60 dentes, diâmetro de $250 \mathrm{~mm}$ e material HW (Metal Duro).

Um riscador, responsável por guiar o corte, também é utilizado neste processo. Não estará sendo levantados seus aspectos, pois não é objeto de estudo deste trabalho uma vez que o acabamento do corte é determinado pela serra que faz o seccionamento da chapa de MDF.

A montagem do conjunto serra e riscador, instalados na máquina pode ser observada na Figura 2.

Figura 2 - Conjunto serra e riscador, instalados na máquina seccionadora de placas de MDF

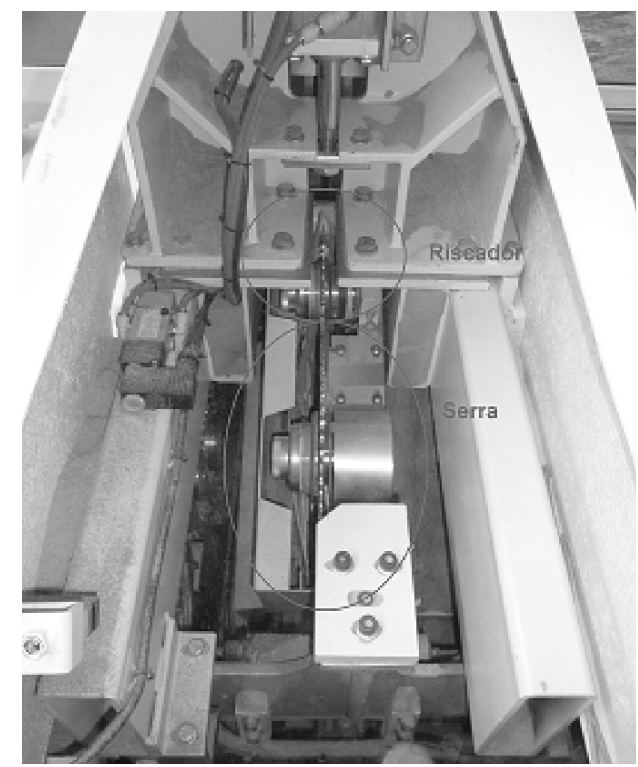

Fonte: Próprio autor. 


\section{Desenvolvimento do Trabalho}

Inicialmente foi observado o setor produtivo, observou-se que a vida útil das ferramentas é determinada de forma intuitiva, ou seja, a cada 15 dias ela é substituída.

De maneira cognitiva o processo de análise e tomada de decisão para a determinação do momento de efetuar o set-up na máquina não obedecia a uma metodologia ou um embasamento científico para tal.

Desta forma também não é levado em consideração o volume de produção. Uma vez que este volume é flutuante, pois em um período podese cortar muito e em outro não.

Mesmo com esse conhecimento do setor produtivo, as necessidades de trocas eram baseadas de maneira intuitiva e cognitiva ou somente quando a qualidade aparente dos produtos finais começava a ser comprometida.

A Figura 3 mostra um defeito classificado como de qualidade aparente pelo setor produtivo devido ao grande volume de produção antes que fosse efetuada a troca da ferramenta intuitivamente.

Figura 3 - Borda de uma chapa de MDF lascada.

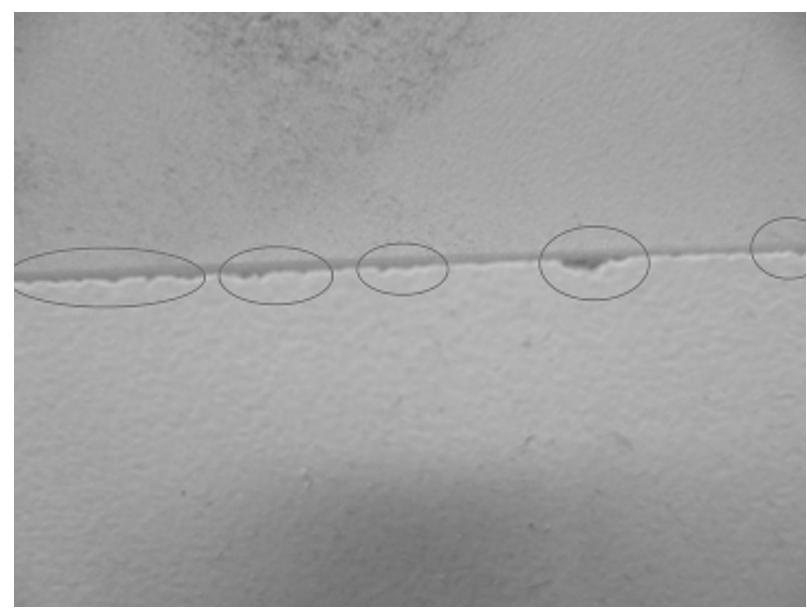

Fonte: Próprio autor.
Tal defeito é decorrente do desgaste da ferramenta de corte, mais especificamente no estado de afiação de seus dentes.

Um comparativo pode ser feito com a Figura 3, onde o padrão desejado é apresentado na Figura 4.

Figura 4 - Borda de uma chapa de MDF em perfeito estado após o corte.

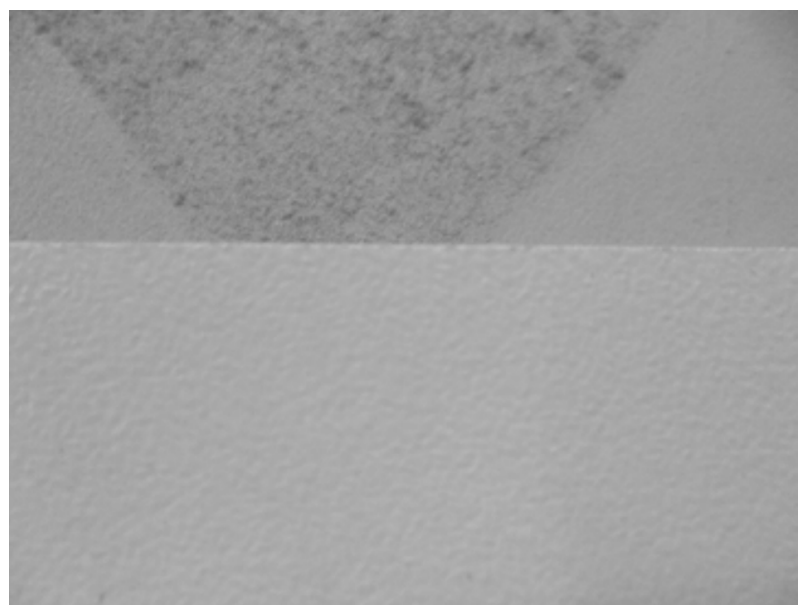

Fonte: Próprio autor.

A qualidade aparente do corte é comprometida devido à mudança morfológica das arestas cortantes dos dentes das serras.

Quando a qualidade aparente dos produtos finais começarem a ser comprometidas, uma atividade normal por parte da produção era a diminuição da velocidade da linha de produção.

É uma maneira de controlar este defeito nos materiais, mas é uma forma paliativa de tratar o problema, pois, quando esta atitude é tomada por parte da produção é sinal que a ferramenta já esta começando a apresentar aspectos de desgaste.

O problema gerado nesta atividade é a diminuição da capacidade produtiva do setor e consequentemente uma redução na produção geral do dia e até a redução da produção global do mês.

Se os prazos estivem curtos para serem atendidos, os clientes poderão ficar sem seus produtos e caso 
a gerencia determine que a produção chegue no resultado de produção esperado terá que arcar com custos de horas extras, reduzindo assim seu lucro.

\section{Custos de Produção}

Foram levantados os custos inerentes a produção relacionada à afiação das ferramentas existentes e a aquisição de novas ferramentas para o processo de usinagem de painéis de madeira reconstituída do tipo MDF.

O custo da ferramenta de HW é de R $\$ 215,00$ sua afiação de R $\$ 0,30$ o dente que corresponde a R $\$ 18,00$ por afiação, o tempo para transporte, afiação e transporte novamente é de10 a 12 dias. Esta ferramenta suporta até 13 afiações depois disso a mesma deve ser descartada, pois, a sua geometria é comprometida devido à retirada de material do processo de afiação.

\section{Parâmetros Obtidos em Campo}

A Figura 5 ilustra a relação Tensões x Peças cortadas onde atenção não sofreu alterações consideráveis ao longo das peças cortadas.

As alterações apresentadas são da própria concessionária de distribuição de energia elétrica local não tendo relação com os outros equipamentos e máquinas presentes na empresa.

Foram verificadas as condições de instalação elétrica da máquina estudada e não foi constatado nenhum fator que influenciasse nos resultados.

Figura 5 - Tensões x Peças cortadas.

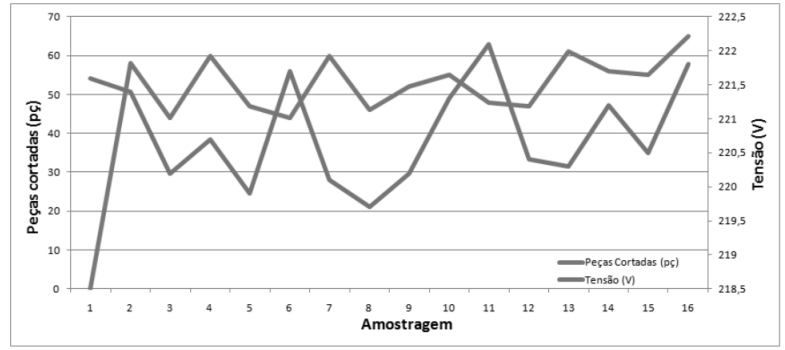

Fonte: Próprio autor.
A Figura 6 ilustra a relação Correntes x Peças cortadas onde foi constatado um aumento da corrente em função do aumento das peças cortadas.

Figura 6 - Correntes x Peças cortadas.

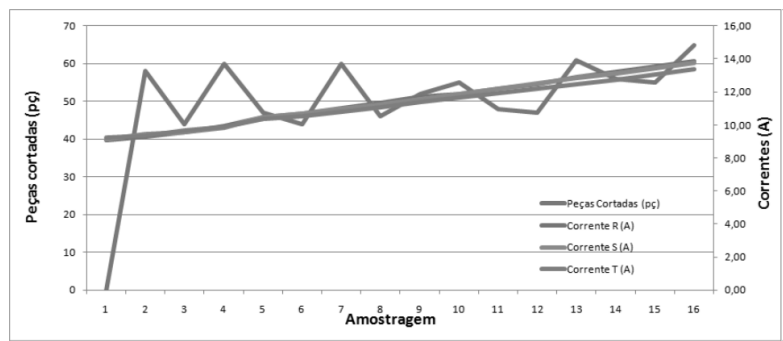

Fonte: Próprio autor.

Este aumento da corrente está relacionado à mudança morfológica do estado das arestas cortantes da ferramenta, pois a mesma vai sofrendo alterações a medida que o acumulo de peças vai avançando.

Com a Figura 7 pode-se observar a relação Temperatura do motor $\mathrm{x}$ Peças cortadas onde se observa um pequeno aumento da temperatura do motor em função do aumento das peças cortadas devido a aumento da potência.

Figura 7 - Temperatura do motor x Peças cortadas.

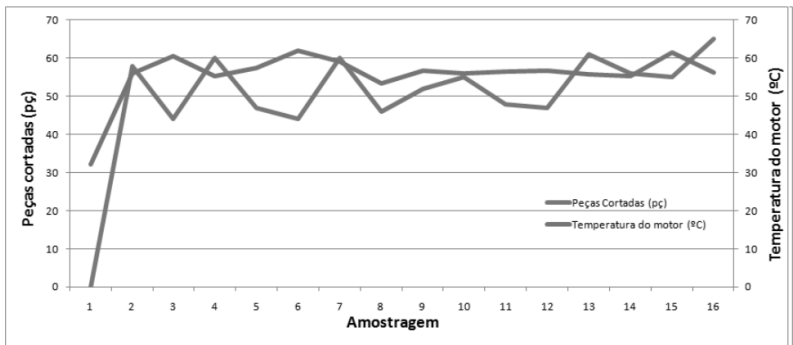

Fonte: Próprio autor.

Com a Figura 8 pode-se observar a relação Temperatura do contato do motor $\mathrm{x}$ Peças cortadas onde pode-se ver um pequeno aumento da Temperatura do contatos do motor em função do aumento das peças cortadas devido ao aumento da corrente que circula por eles. 
Figura 8 - Temperatura do contatos do motor $\mathrm{x}$ Peças cortadas.

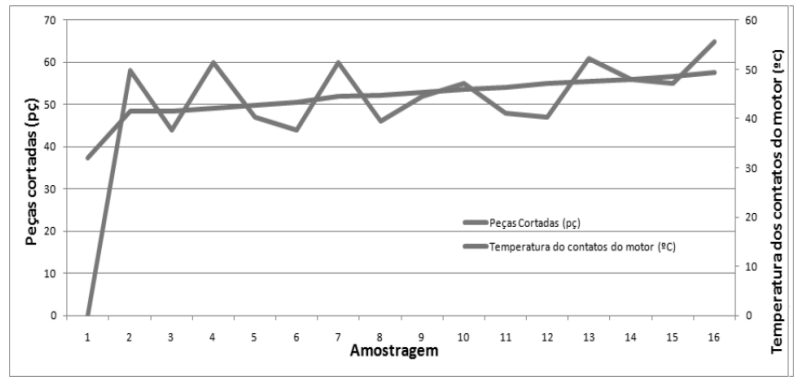

Fonte: Próprio autor.

Temperatura da ferramenta durante o corte pode ser observada na Figura 9 onde seu comportamento sofreu pequenas alterações na temperatura, uma vez que a máquina fica muito tempo ociosa.

Figura 9 - Temperatura da ferramenta durante o corte $\mathrm{x}$ Peças cortadas.

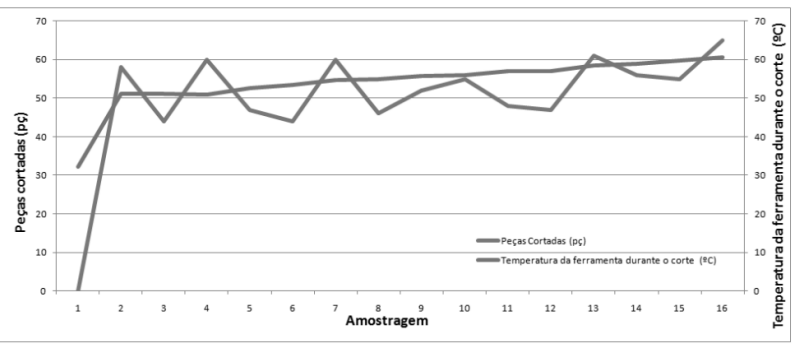

Fonte: Próprio autor.

Temperatura ambiente apresentada na Figura 10 é importante para ser comparada caso ocorresse um aquecimento no motor e na temperatura durante o corte.

Figura 10 - Temperatura ambiente x Peças cortadas.

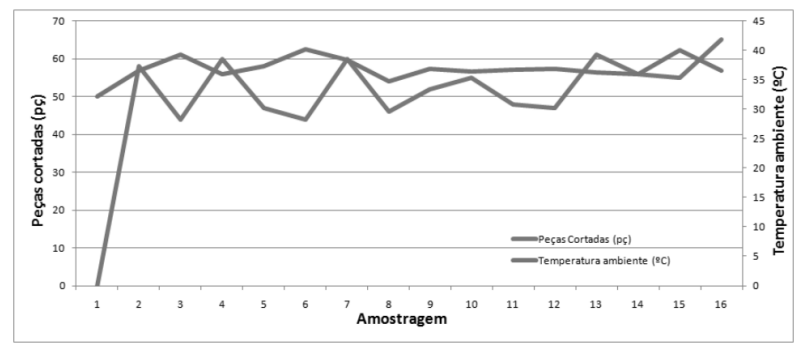

Fonte: Próprio autor.
O Ângulo antes x Ângulo depois, importante uma vez que a peça começou com $22^{\circ}$ e finalizou com os mesmos $22^{\circ}$.

A Figura 11 mostra o projetor de perfil sendo utilizado para a aferição do ângulo de corte e a Figura 12 obtida do microscópio é a aresta cortante da ferramenta.

Na Figura 13, também depois de ser retirada da máquina após a produção, também foi aferido os mesmos 22o a mudança que ocorreu foi em sua morfologia na aresta cortante como pode ser vista na Figura 14.

A Figura 15 relaciona a Potência elétrica x Peças cortadas onde pode ser observado o acúmulo de potencia em função das peças cortadas.

Um ponto de partida para a determinação dos custos de produção foi a Figura 16 onde pode ser observada a potência nominal do motor, a potência durante o corte com a serra nova e a potencia durante o corte com a ferramenta desgastada.

Consumo de energia elétrica x Peças cortadas é visto na Figura 17.

O ponto isolado no gráfico é o consumo nominal do motor operando sem efetuar o corte, simplesmente girando a serra.

Figura 11 - Aferição do ângulo da serra antes da utilização.

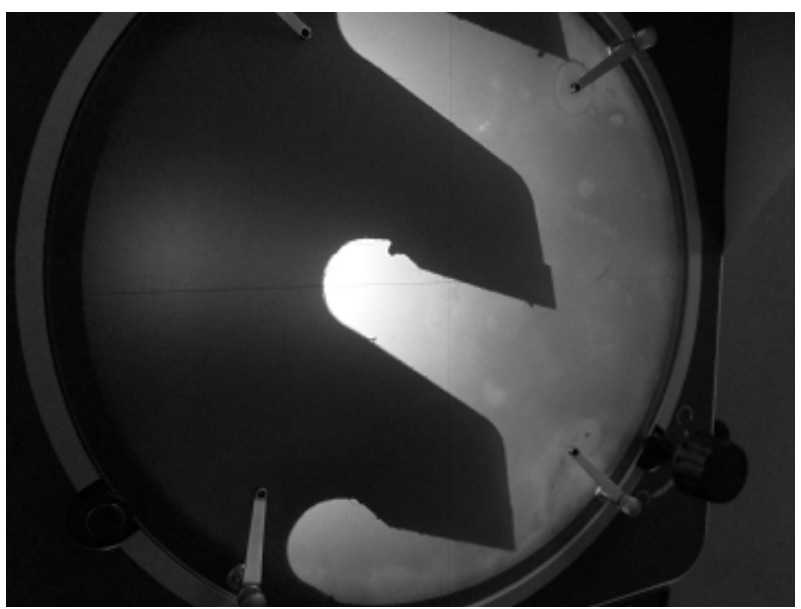

Fonte: Próprio autor. 
Figura 12 - Aferição da aresta cortante antes da utilização.

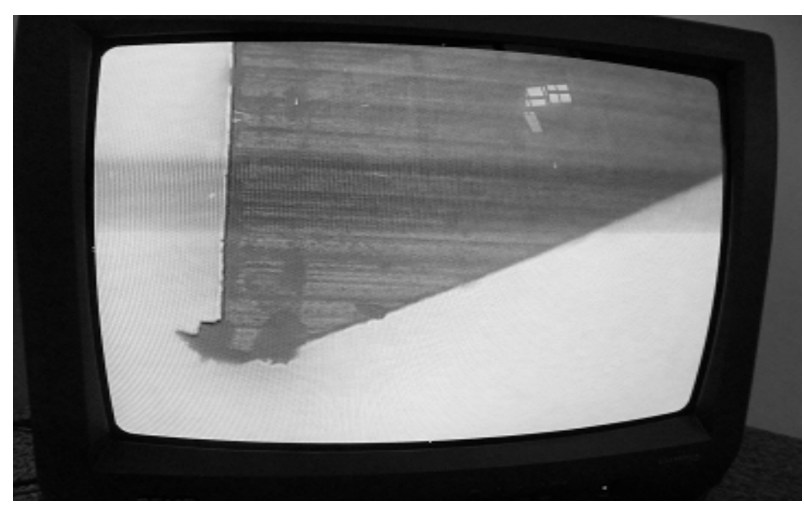

Fonte: Próprio autor.

\section{Conclusões}

Pode-se observar que existe um momento em que a corrente e a potencia começaram a subir consideravelmente devido o aumento do torque do motor a medida que a ferramenta está se desgastando, tal ponto é onde o motor começou a ser mais solicitado perante a sua potencia, comportandose assim como um grande consumidor de energia elétrica em potencial e ultrapassando os custos de afiação da ferramenta.

A Figura 18 ilustra esta situação onde foram relacionados os resultados das variáveis coletadas durante a pesquisa de campo.

O valor futuro está sendo acrescido o valor da afiação que é de $\mathrm{R} \$=18,00$ e está sendo graficamente invertido em função do consumo de energia elétrica, assim no ponto em que os dois gráficos se cruzam é o ponto ótimo de operação.

O ponto ótimo de operação para este trabalho foi obtido entre as amostragens 13 e 14.
Figura 13 - Aferição do ângulo da serra depois da utilização.

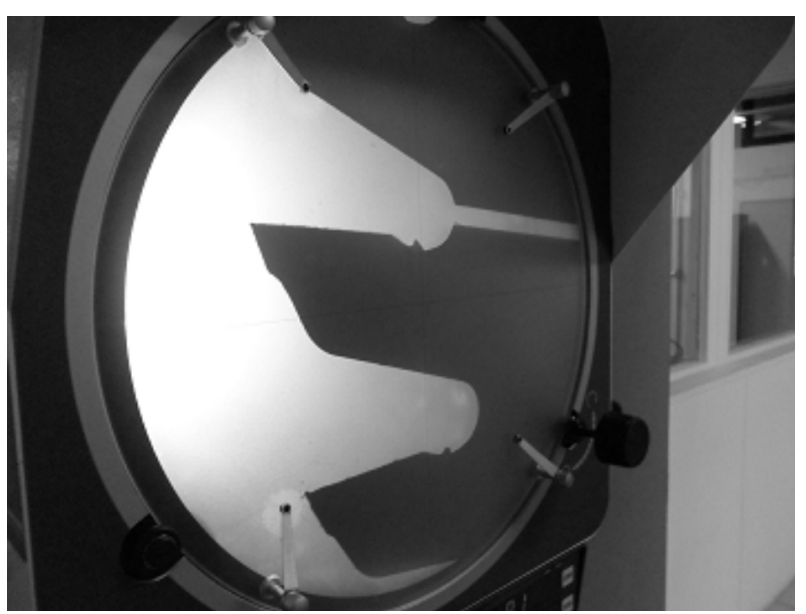

Fonte: Próprio autor.

Figura 14 - Aferição da aresta cortante depois da utilização.

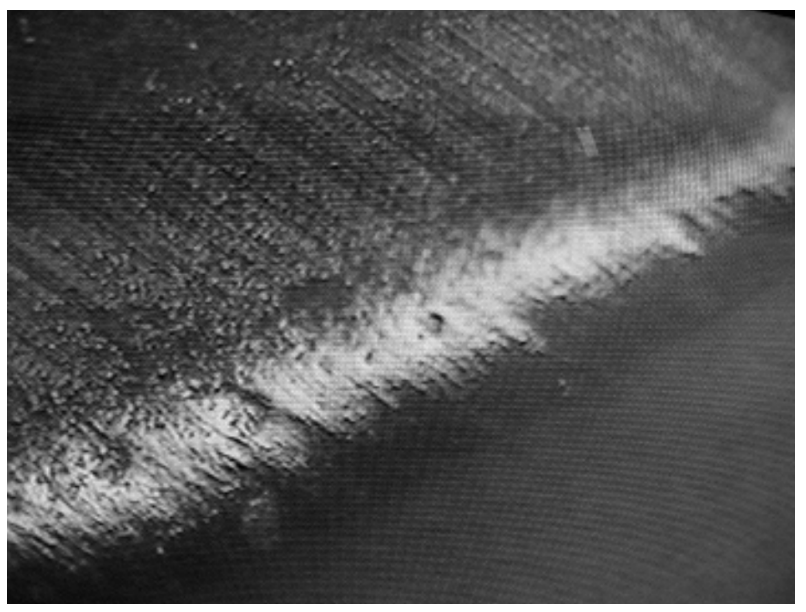

Fonte: Próprio autor.

Figura 15 - Potencia elétrica x Peças cortadas.

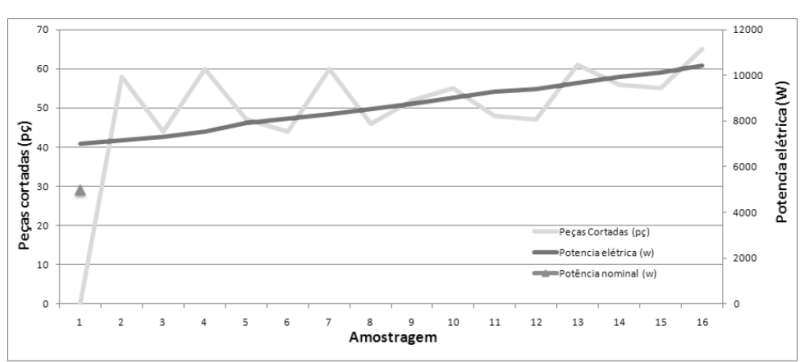

Fonte: Próprio autor. 
$\mathrm{Na}$ amostragem 13 o valor da operação ainda não chegou ao valor dos gastos com a afiação da ferramenta.

Já para a amostragem 14 o valor da operação do corte superou o preço de afiação da ferramenta.

Figura 16 - Comparativo entre as potencias.

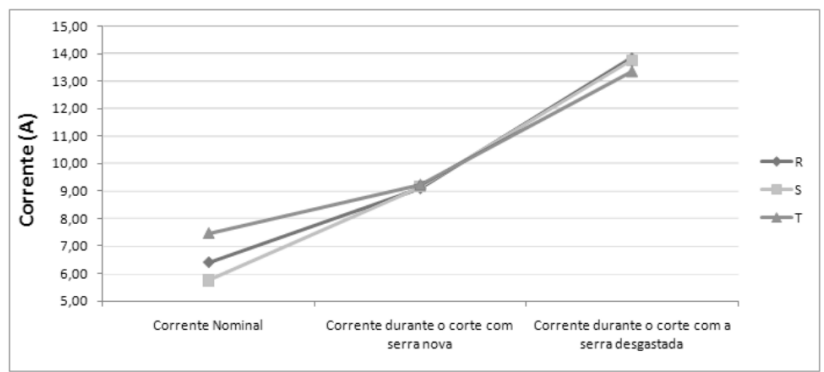

Fonte: Próprio autor.

Figura 17 - Consumo de energia elétrica x Peças cortadas.

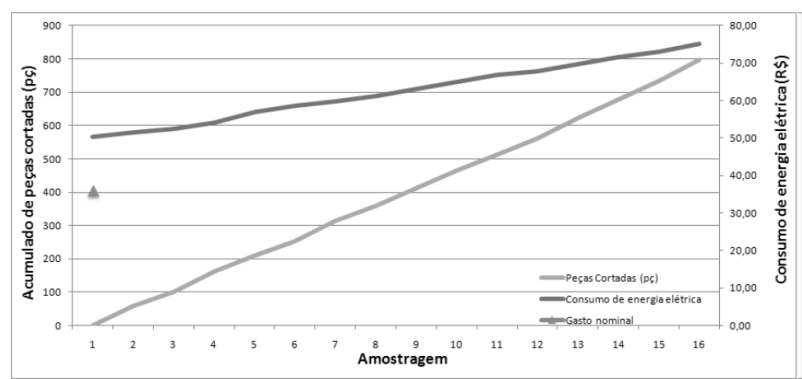

Fonte: Próprio autor.

Figura 18 - Ponto ótimo de operação.

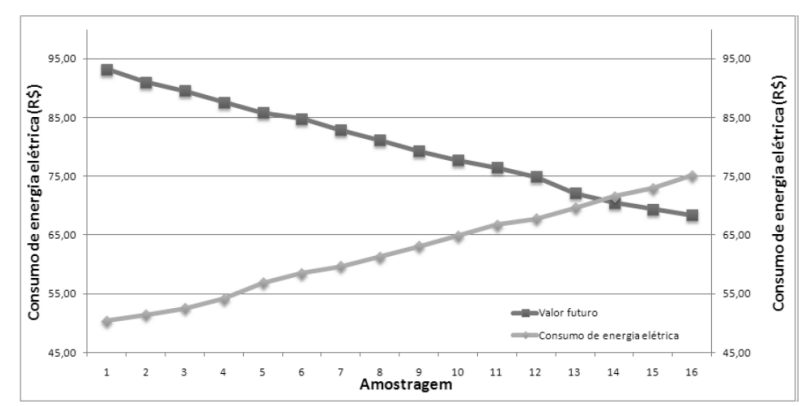

Fonte: Próprio autor.
Nestas situações não foram apresentados os defeitos aparentes nas peças cortadas, mas os gastos com o consumo de energia elétrica justificam a substituição da mesma.

O que ocorre nesta situação é uma falsa percepção que o processo é o mais econômico.

De forma prática pode ser observado o comportamento de um motor de indução trifásico instalado em uma seccionadora de placas de madeira reconstituída do tipo MDF perante o consumo de energia elétrica.

O estudo realizado é de suma importância para ser baseado como material didático na determinação do ponto ótimo de produção em máquinas de manufatura mecânica de usinagem de materiais.

$\mathrm{Na}$ pesquisa que foi apresentada foram evidenciados pontos e fatos relevantes quanto ao favorecimento de linhas de manufatura de móveis para o setor moveleiro.

Cada máquina e/ou equipamento deve ter o seu estudo de maneira individual, uma vez que devem ser consideradas as particularidades de cada processo.

Devido a máquina estar muito tempo ociosa alguns dados não foram relevantes para a determinação do ponto ótimo de operação. Pontos estes que estão relacionados com as aferições de temperatura durante a operação.

Com um grande propósito não só no consumo de energia elétrica, a qualidade aparente dos produtos final deixou de ser o único parâmetro para a determinação da substituição da ferramenta desgastada.

A pergunta sobre o ponto ótimo de operação foi respondida antes do momento em que a qualidade aparente dos produtos começasse a ser comprometida, assim as tomadas de decisões sobre diminuição do avanço sobre a peça ou substituição da ferramenta foram encontradas uma vez que se sabe o valor para a afiação e quanto de energia elétrica foi consumido. 
Uma maneira que pode ser adotada para a determinação do ponto ótimo de operação em uma máquina e ou equipamento é instalação um amperímetro na linha de produção para a determinação do momento para a substituição da ferramenta.

Devem-se observar as correntes do motor operando deforma nominal, com a ferramenta nova e depois com a ferramenta desgastada.

Assim um comparativo pode ser feito e parametrizado com os estudos realizados neste trabalho.

\section{Referências}

FERRARESI, D. Fundamentos da usinagem dos materiais. São Carlos: Edgar Blucher, 1977.

MAMEDE FILHO, J. Instalações elétricas industriais. Rio de Janeiro: LTC, 2007.

GITMAN, L.; JUCHAU, R.; FLANAGAN, J. Principles of managerial finance. Boston: AddisonWesley, 2000.

ISHIKAWA, K. Controle de qualidade total: à maneira japonesa. Rio de Janeiro: Campus, 1993.

LEÃO, S.; SANTOS, M. Aplicação da troca rápida de ferramentas (TRF) em intervenções de manutenção preventiva. Produção Online, v. 9, n. 1, p. 1-27, 2009.

REIS, L. B.; CUNHA, E. C. N. Energia elétrica e sustentabilidade: aspectos tecnológicos, socioambientais e legais. Barueri: Manole, 2006.

SLACK, N.; CHAMBERS, S.; JOHNSTON, R. Administração da produção. 2. ed. São Paulo: Atlas, 2008.

YIN, R.; GRASSI, D. Estudo de caso: planejamento e métodos. Porto Alegre: Bookman, 2001. 